\title{
Experimental and Computational Investigations of Phase Change Thermal Energy Storage Canisters
}

\author{
Mounir Ibrahim \\ Cleveland State University \\ Cleveland, Ohio \\ Thomas Kerslake \\ Lewis Research Center \\ Cleveland, Ohio \\ Pavel Sokolov \\ Cleveland State University \\ Cleveland, Ohio \\ Carol Tolbert \\ Lewis Research Center \\ Cleveland, Ohio
}

Prepared for the

International Congress of Fluid Dynamics and Propulsion

sponsored by the American Society of Mechanical Engineers and Cairo University Cairo, Egypt, December 29-31, 1996

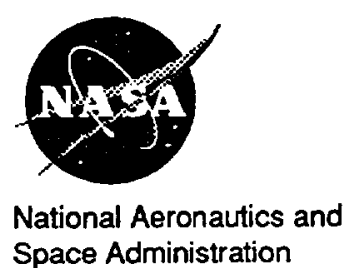

Space Administration 



\section{Experimental and Computational Investigations \\ of}

Phase Change Thermal Energy Storage Canisters

\author{
Mounir Ibrahim \\ Cleveland State University \\ Cleveland, $\mathrm{OH} 44115$ \\ Pavel Sokolov \\ Cleveland State University \\ Cleveland, $\mathrm{OH} 44115$
}

\section{ABSTRACT}

Two sets of experimental data were examined in this paper, ground and space experiments, for cylindrical canisters with thermal energy storage applications. A 2-D computational model was developed for unsteady heat transfer (conduction and radiation) with phase-change. The radiation heat transfer employed a finite volume method. The following was found in this study: 1) Ground Experiments, the convection heat transfer is equally important to that of the radiation heat transfer; Radiation heat transfer in the liquid is found to be more significant than that in the void; Including the radiation heat transfer in the liquid resulted in lower temperatures (about $15 \mathrm{~K}$ ) and increased the melting time (about $10 \mathrm{~min}$.); Generally, most of the heat flow takes place in the radial direction. 2) Space Experiments, Radiation heat transier in the void is found to be more significant than that in the liquid (exactly the opposite to the Ground Experiments); Accordingly, the location and size of the void affects the performance considerably; Including the radiation heat transfer in the void resulted in lower temperatures (about $40 \mathrm{~K}$ ).

\section{Nomenclature}

$\begin{array}{ll}A & \text { surface area } \\ c & \text { material specific heat } \\ D_{c} & \text { directional cosine } \\ e & \text { enthalpy } \\ g & \text { gravitational acceleration } \\ H_{m} & \text { PCM heat of fusion } \\ h & \text { heat transfer coefficient } \\ \text { I } & \text { radiative intensity } \\ I_{b} & \text { blackbody intensity } \\ \mathbf{K} & \text { thermal conductivity } \\ \mathrm{Nu} & \text { Nusselt number } \\ \mathrm{q} & \text { heat flux } \\ r & \text { radial coordinate } \\ r & \text { position vector } \\ \mathrm{S} & \text { radiative source function }\end{array}$

\author{
Thomas Kerslake \\ NASA Lewis Research Center \\ Cleveland, $\mathrm{OH} 44135$
}

\author{
Carol Tolbert \\ NASA Lewis Research Center \\ Cleveland, $\mathrm{OH} 44135$
}

\begin{tabular}{|c|c|}
\hline$S_{m}$ & $\begin{array}{l}\text { modified radiative source } \\
\text { function }\end{array}$ \\
\hline $\mathbf{s}$ & direction vector \\
\hline 1 & temperature \\
\hline$T_{0}$ & $\begin{array}{l}\text { cooling fluid inlet } \\
\text { temperature }\end{array}$ \\
\hline $\begin{array}{l}T_{f} \\
T_{m}\end{array}$ & $\begin{array}{l}\text { cooling fluid temperature } \\
\text { PCM melting point }\end{array}$ \\
\hline$t$ & time \\
\hline$u$ & $\begin{array}{l}\text { overall heat transfer } \\
\text { coefficient }\end{array}$ \\
\hline v & volume \\
\hline$v$ & velocity of the liquid PCM \\
\hline$x_{f}$ & $P C M$ quality $=e / H_{m}$ \\
\hline $\mathbf{z}$ & axial coordinate \\
\hline$z_{\text {rad }}$ & $\begin{array}{l}z \text {-coordinate of the } \\
\text { radiator emitting surface }\end{array}$ \\
\hline$\alpha$ & absorption coefficient \\
\hline$\beta$ & extinction coefficient \\
\hline$\beta_{m}$ & $\begin{array}{l}\text { modified extinction } \\
\text { coefficient }\end{array}$ \\
\hline$\rho$ & density \\
\hline$\varepsilon$ & emissivity \\
\hline$\Phi$ & scattering phase function \\
\hline$\sigma$ & $\begin{array}{l}\text { scattering coefficient } \\
\text { (Stefan-Boltzman } \\
\text { constant in equation (10)) } \\
\text { solid anale }\end{array}$ \\
\hline$\Omega$ & le \\
\hline
\end{tabular}

Subscripts and superscripts

$\begin{array}{ll}\text { b } & \text { bottom } \\ \text { E } & \begin{array}{l}\text { finite volume to the right of } \\ \text { the control volume } \\ \end{array} \\ \text { eff } & \text { effective } \\ \text { L } & \text { liquid } \\ \mathrm{m} & \text { metal } \\ \mathrm{mz} & \text { mushy zone } \\ \mathrm{o} & \text { outer } \\ \mathrm{rad} & \text { radiative } \\ \mathrm{s} & \text { solid } \\ \mathrm{t} & \text { top }\end{array}$




\section{INTRODUCTION}

Freezing and melting due to heat transfer take place in different engineering applications. At present time, phase-change phenomena have become an indispensable part of many processes, for example, manufacturing of glass crystals, and metal alloys, casting processes, food preservation and cryopreservation of biological cells, just to name a few. A recent review of the freezing and melting process was provided by Yao and Prusa (1989). On the other hand there are several engineering applications which involve energy demand at a later period than its supply, which requires a thermal storage system. The choice of an appropriate storage system is most frequently between using a Sensible Heat Storage (SHS) material and Phase-Change Material (PCM). A review of the two systems has been provided by Beasley and Clark (1984). nvestigations of PCM systems have been provided by Beasley et al (1989), Kerslake and Ibrahim (1993), \& (1994) and Adebiyi (1991). Recently more experimental data have been obtained for ground PCM system, Kerslake (1991), as well as Thermal Energy Storage (TES) experiments conducted on the Shuttle Columbia. These efforts were part of the development of Solar Dynamic Systems in space and were provided for different canister design, material, dimensions and type of salt.

Several studies were conducted to utilize the available experimental data for both the ground testing and the space ones, in order to provide a better understanding for the phase-change process. Kerslake (1991) simulated the ground experiment while Namkoong et al (1995) simulated the TES-1 space experiment. The motivation of this study is to further enhance the computational capabilities and physical understanding of the phenomena by including a proper modeling of the void in the canister. Further more, the radiation heat transfer analyses, in both the void and the PCM liquid, were improved by using a finite volume method Chai et al (1994). In this paper, a systematic approach has been taken for the modeling process. The predictions of the temperature history will be obtained with no radiation, radiation in the void, radiation in the void and the liquid. The predictions will be evaluated against the experimental data. One of these data sets were conducted at NASA Lewis Research Center (Ground Experiments), the other was part of the OAST-2 Hitchhiker payload on the Columbia Shuttle STS-62 in early 1994
(Space Experiments). Detailed information about the Ground Experiments can be found in Kerslake (1991), while those for the Space Experiments can be found in Namkoong et al (1995). The physical characteristics of the canisters used in the two experiments are given in Table I.

\section{Numerical Analysis}

\subsection{Geometry and Boundary Conditions}

\subsubsection{Ground Experiments}

The temperature and density distributions in the system are assumed to be axisymmetric which reduces the problem to a 2-dimensional cylindrical geometry $(r, z)$. The geometry of the problem is shown on Figure 1. The void is considered to be in the region adjacent to the top wall, consistent with the experimental observations when the canister was in the vertical position. The volume fraction of the void is $30 \%$ of the total canister volume. The void's volume and shape are assumed to be constant.

The top and the bottom walls of the canister are insulated. Heating is provided by a heater on the outside wall. The heat flux is uniform and periodic in time. The effective heating power which is the difference of the heater power and the power of the radiative heat loses between the canister and the test chamber was computed by Kerslake (1991) and shown in Figure 2.

Cooling of the canister is provided by cooling air, flowing in the inside tube. The air inlet temperature is also provided by Kerslake (1991).

\subsubsection{Space Experiments (TES1)}

The geometry of the TES1 experiment is illustrated on Figure 3 . Since the TES1 experiment was performed in a microgravity environment, the location of the void is controlled by the surface tension rather than the gravity force. Because of the Marangoni effect, the void tends to be in the hottest region of the canister that is the outer lower corner in this problem (Namkoong et al. (1995)). The void's volume fraction is $15 \%$.

Again the top and the bottom sides of the canister are insulated. Heating is provided by a heater on the outside wall of the canister. Similar to the ground experiment, the effective heating power can be estimated (Figure 4). Cooling is done by radiation from the surface of a circular disk (radiator) attached to the 
canister via a conductor rod. The boundaries of the rod and the radiator are insulated except for the radiating surface of the radiator.

In both experiments, the objective is to determine the temperature distribution in the system. The following four cases are considered: (1) neither the void nor the liquid $\mathrm{PCM}$ are transparent to the thermal radiation; (2) the void is transparent but the liquid PCM is not; (3) both the void and the liquid PCM are transparent. (4) same as case (3) but the liquid PCM absorbs the thermal radiation with an absorption coefficient of $0.84 \mathrm{~cm}^{-1}$.

The similarities and differences of the temperature distributions in the four cases are of a particular interest along with evaluation of the computational results against the experimental data.

\subsection{Governing equations}

PCM, walls, conduction rod and radiator

The enthalpy formulation of the heat transfer equation is used. This approach has proved to be effective for problems with solid-liquid phase change (Kerslake and Ibrahim (1993), Wichner et. al. (1988), Solomon and Wilson (1986)). The conservation of energy equation in this approach becomes:

$$
\left(\frac{\partial}{\partial t}+v \cdot \nabla\right)(\rho e)=\nabla \cdot(k \nabla T)-\nabla \cdot q_{\text {rad }}
$$

This approach eliminates the need to introduce an infinitely large heat capacitance in the melting region to insure the isothermal melting. The enthalpy is connected to the temperature via the constitutive equations:

$$
T=\begin{array}{lll}
T_{m}+e / c_{s} & : e<0 \quad \text { (solid } P C M) \\
T_{m} & : 0 \# \text { e\# } H_{m} \text { (mushy } P C M \text { ) } \\
T_{m+\left(e-H_{m}\right) / c_{L}}: H_{m}<e \text { (liquid } P C M \text { ) } \\
T_{m}+e / c_{m} & :-4 \# \text { e\#4 (metal parts) }
\end{array}
$$

Indeed, the temperature stays constant and equal to the melting temperature in the so-called Amushy zone@ which can be viewed as a transition zone between the solid and the liquid phases. The second term of equation (1) is a transport term and it contains the velocity of the liquid phase. The velocity distribution in the liquid PCM is governed by the gravity and surface tension of the liquid-void interface. Determining this distribution is complicated and, most importantly, time consuming. Since we are interested mostly in the global heat transfer, the natural convection in the liquid PCM is modeled using the existing empirical correlations. The common approach is to estimate the enhancement of the value of the liquid PCM thermal conductivity such that:

$$
k_{L, e f f}=N u k_{L}
$$

The liquid PCM will be shown to be present in the problems considered in this study in the form of a vertical layer. Therefore, the correlation for a vertical layer with isothermal or isoflux boundary conditions by Ozisik (1985) is used.

The effective conductivities of the solid PCM and the metal parts are equal to their normal values, the liquid effective conductivity is computed using equation (3), and the effective conductivity of the mushy PCM is treated as a linear function of the PCM quality $x_{F}=e / H_{m}$ :

$$
k_{m z, e f f}=\left(1-x_{f}\right) k_{s}+x_{f} k_{L, e f f}
$$

The liquid PCM (LiF) has been found (Wichner (1987)) to be transparent to the thermal radiation for wave-lengths $\leq 5.5 \mu \mathrm{m}$ and semi-transparent for wave-lengths $>5.5 \mu \mathrm{m}$. The average Rosseland absorption coefficient is virtually constant in the temperature interval of interest $(1000 \mathrm{~K}-1200 \mathrm{~K})$ and equal to $0.84 \mathrm{~cm}^{-1}$ (Wichner (1987)). It is of one's interest to examine both the transparent and the semitransparent models of the liquid PCM. Note that in the former case the last term of equation (1) becomes zero, since it can be shown that the divergence of the radiative heat flux is proportional to the absorption coefficient for a uniform medium (see also equation (14) below). However, the radiative heat flux can be nonzero in the case of the transparent medium, although its divergence is zero. Therefore, this heat flux has been computed and used in the energy balance equations for the solid PCM and walls finite volumes adjacent to the liquid PCM layer.

Void

The void is assumed to be filled with the LiF$\mathrm{CaF}_{2}$ vapor in the Ground Experiments and the LiF vapor in the Space Experiments with negligible thermal capacity and absorption coefficient. Hence, the heat transfer equation in the void is

$$
\nabla \cdot(k \nabla T)=0
$$

Similarly to the liquid PCM model, the radiative heat flux in the void can be non-zero, although its divergence is zero due to the negligible absorption coefficient. Therefore, this heat flux has been computed and used in the energy 
balance equations of the PCM and walls finite volumes adjacent to the void.

\section{Boundary conditions}

The following three boundary conditions in the experiments have been applied:

(a) The "heating" boundary condition at the outside wall:

$$
r=r_{0}:-k_{m} \frac{\partial T}{\partial r}=q_{i n}
$$

(b) The insulation boundary condition at the top and the bottom walls:

$$
z=z_{t}, z_{b}:-k_{m} \frac{\partial T}{\partial z}=0
$$

(c) The "cooling" boundary conditions are different in each experiment.

(c1) Ground Experiments:

$$
r=r_{i}:-k_{m} \frac{\partial T}{\partial r}=u\left(T-T_{f}(z)\right)
$$

The cooling air temperature is determined by utilizing the time-dependent inlet profile (Kerslake (1991)) and assuming a linear temperature distribution in the z-direction.

(c2) Space Experiments:

$$
\begin{gathered}
r=0: \frac{\partial T}{\partial r}=0 \\
z=z_{\mathrm{rad}}:-k_{m} \frac{\partial T}{\partial z}=\sigma \varepsilon_{m}\left(T^{4}-T_{\text {sink }}^{4}\right)
\end{gathered}
$$

$T_{\text {sink }}$ is the temperature of the surrounding.

Initial condition

Initially, the system is assumed to be at a uniform temperature in both experiments. The initial temperature is $922 \mathrm{~K}$ in the Ground Experiments and $283 \mathrm{~K}$ in the Space Experiments.

\subsection{Numerical method}

The simple explicit method is used to solve equation (1). However, the heat transfer equation in the void (5) is elliptic in contrast with the PCM heat transfer equation, which is parabolic. Therefore, a simple explicit method cannot be used, and the successive overrelaxation (SOR) by lines procedure, for the Laplace equation (Anderson et. al. (1984)), has been utilized .

\section{The radiation model}

The Finite Volume Method (FVM) developed by Chai et al. (1994) has been used to compute the radiative heat flux. The equation of radiative heat transfer can be written in terms of the radiative intensity $I(r, s)$ and the source function $S(\mathbf{r}, \mathbf{s})$ (Modest (1993)):

$$
\frac{d l(r, s)}{d s}=-\beta(r) /(r, s)+s(r, s)
$$

where $\beta(r)=\alpha(r)+\sigma(r)$ is the extinction coefficient, $\alpha(r)$ is the absorption coefficient, $\sigma(r)$ is the scattering coefficient, and

$$
S(r, s)=\alpha(r) I_{b}(r)+\frac{\sigma(r)}{4 \pi} \int_{4 \pi} I\left(r, s^{\prime}\right) \phi\left(s^{\prime}, s\right) d \Omega^{\prime}
$$

In these equations, $r$ is the position vector and $s$ is the directional vector. If equation (11) together with emissive boundary conditions (see Modest (1993)) is solved then one can compute the radiative heat flux and its divergence via the following equations:

$$
\begin{gathered}
q(r)=\int_{4 \pi} l(r, s) s d \Omega \\
\nabla \cdot q(r)=\alpha\left(4 \pi / b(r)-\int_{4 \pi} l(r, s) d \Omega\right)
\end{gathered}
$$

To solve equation (11) numerically, the coordinate space is discretized into finite volumes in the usual manner. Since the intensity I depends also on the angular direction, the angular space should be discretized as well. In the present method, the angular space is divided into solid angles.

Integrating equation (11) over a control finite volume $\Delta V$ and a control solid angle $\Delta \Omega^{1}$ and using the divergence theorem, we obtain

$$
\int_{\Delta \Omega^{\prime}} \int_{\Delta A} I^{\prime}\left(s^{\prime} \bullet n\right) d A d \Omega^{\prime}=\int_{\Delta \Omega^{\prime}} \int_{\Delta V}\left(-\beta I^{\prime}+S^{\prime}\right) d V d \Omega^{\prime}
$$

where $\triangle A$ is the surface bounding the control volume $\Delta V$. Following the FVM, the intensity is assumed to be constant within the control volume and the control angle. Hence equation (15) becomes in a 2-D axisymmetric system:

$$
\sum_{i=1}^{4} l_{i}^{\prime} D A_{i} \int_{\Delta \Omega^{\prime}}\left(s^{\prime} \cdot n_{i}\right) d \Omega^{\prime}=\left(-\beta_{m}^{\prime} l^{\prime}+s_{m}^{\prime}\right) \Delta V \Delta \Omega^{\prime}
$$

where the summation is performed over the four faces of the control volume, and the modified extinction coefficient and the source function are: 


$$
\begin{gathered}
\beta_{m}=\beta-\frac{\sigma}{4 \pi} \phi^{\prime, l} \Delta \Omega^{\prime} \\
S_{m}^{\prime}=\alpha I_{b}+\frac{\sigma}{4 \pi} \sum_{l^{\prime} \neq 1} \phi^{l^{\prime}, l} \Delta \Omega^{l^{\prime}} l^{\prime}
\end{gathered}
$$

One can solve equation (16) for the intensity in the center $\mathbf{P}$ of the control volume

$$
I P=\frac{(1-\Delta r / 2 r P) \Delta z D_{c r}^{\prime} l_{W}^{\prime}+\Delta r D_{c r}^{\prime} l_{S}^{\prime}+s_{m P \Delta r \Delta z \Delta \Omega^{\prime}}^{\prime}}{(1+\Delta r / 2 r P) \Delta z D_{c r}^{\prime}+\Delta r D_{c z}^{\prime}+\beta_{m P}^{\prime} \Delta r \Delta z \Delta \Omega^{\prime}}
$$

where the subscripts " $\mathrm{P}$ ", "W", and "S" denote the points $\{i\},\},\{i-1, j\}$, and $\{i, j-1\}$ respectively, and

$$
D_{c i}^{\prime}=\int_{\Delta \Omega^{\prime}}\left(s^{\prime} \cdot n_{i}\right) d \Omega^{\prime}
$$

is either the $\mathrm{r}$ - or the $\mathrm{z}$-directional cosine.

Chai et al. (1994) modified equation (17) by exponentially extrapolating the intensity at the neighboring nodes to the sides of the control surface $\Delta \mathrm{A}$. Their procedure increases the accuracy of the scheme and eliminates the possibility of a physically incorrect negative intensity. The resulting scheme (Chai et al. (1994) has been used to solve for the radiative intensity and the heat flux.

\section{Results and Discussion.}

\subsection{Ground Experiments.}

\subsubsection{Convergence test.}

Figure 5 shows the comparison of the outside wall temperature predictions from the

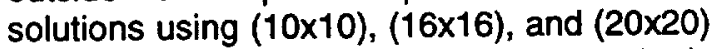
grids $((r, z)$ in the interior canister region). Significant differences in the temperature distribution are noted between grid sizes $(10 \times 10)$ and $(16 \times 16)$ while little difference is found between grid sizes $(16 \times 16)$ and $(20 \times 20)$. Grid size (16x16) has been used in this study.

\subsubsection{Comparison with experimental data.}

Figure 6 shows the comparison of the outside wall temperature predicted by the numerical solution (four cases) with the experimental data. The numerical solutions capture very closely the important features of the temperature distribution, such as the slope during the onephase solid heating (0-15 $\mathrm{min})$, and cooling (65-91 $\mathrm{min}$ ), point of the onset of melting (the distinct slope change at about $15 \mathrm{~min}$ ), the temperature arrest during PCM melting(15-40 $\mathrm{min}$ ) and freezing (55-65 min). A data feature not well predicted by the model is the temperature during one-phase liquid heating $(40-55 \mathrm{~min})$. This could be attributed to a number of reasons: the axisymmetric assumption might have led to underprediction of the time needed to fully melt the PCM, the cooling fluid film coefficient and the liquid PCM Nusselt number might have been underpredicted, the void's size and location were changing in the actual experiment while the numerical model assumed a static void.

\subsubsection{Effect of natural convection in the liquid PCM}

Convection usually lowers the thermal resistance of the fluid thus improving the heat transfer and lowering the temperature gradients. This can be seen from the comparison of the wall temperatures in two situations when the natural convection is assumed to be present or not present (Figure 7). The temperature in the absence of convection is considerably higher than the temperature when the natural convection is present, especially at the time interval when the liquid PCM is present (15$65 \mathrm{~min}$ ). Therefore, the liquid Nusselt number is high during the melting stage but drops considerably in the freezing period. The negative heat fluxes at the inner and the outer walls during the freezing period of the cycle (Figure 2) cause layers of solid PCM to form in the regions adjacent to the inside and the outside walls. The liquid PCM is trapped between these two layers. The temperatures of these layers are close to the melting temperature and thus to each other, hence the Nusselt number is close to 1 .

\subsubsection{Effect of radiation through the void}

Because of the location of the void, its presence and the processes inside it should not be a big factor in the overall heat transfer. This is obvious from the comparison of the temperature histories of the outside wall when the radiation through the void is present and not present (Figure 6, cases (1) and (2)). The radiative heat transfer does lower the temperature as one would expect (since the additional heat flux lowers the thermal resistance of the void), but this improvement is not significant (about 2-5 K) because of the location of the void in this situation. While the processes in the void do not affect the global heat transfer, the void's presence can cause 
the formation of local non-uniformities of temperature ("hot spots"). As seen on Figure 8a, distinctive cold and hot spots are formed on the inside and the outside walls of the canister, respectively, at locations where the void is present.

\subsubsection{Effect of radiation through the liquid PCM}

Since the liquid PCM forms a vertical layer in the canister, the additional heat flux through this layer should improve the overall heat transfer in the system thus lowering the temperatures in the canister. Since the layer is vertical, as opposed to the horizontal configuration of the void, the effects of the radiation through the liquid PCM should be expected to be more significant than those of radiation in the void. It is obvious from Figure 5 that the maximum temperature of the outside wall is lower when the liquid PCM is transparent to the thermal radiation than when it is not by about $18 \mathrm{~K}$. Compared to the $2-5 \mathrm{~K}$ improvement by the void radiative heat flux, this is a much more significant effect. An important effect of the radiation through the liquid PCM and the reason for a lower wall temperature is a longer time needed to melt all the PCM in the canister (see Figure 5). Since the canister thermal resistance becomes smaller due to the radiative heat flux, more energy is transferred from the heater to the cooling fluid through the canister. Hence, a smaller portion of the incoming energy is spent on heating and melting of the PCM, thus a longer time is needed to fully melt the PCM. This portion of energy spent to melt the solid PCM becomes even smaller when the forming liquid PCM absorbs the thermal radiation. This results in an even longer melting time and lower temperatures as seen on Figure 5 . The energy absorbed and stored by the liquid PCM is then released during the freezing part of the cycle which results in a slightly longer freezing time and temperatures.

Overall, the main effect of the radiation through both the void and the liquid PCM is a higher heat flux through the canister and a more uniform temperature distribution in the canister. Comparison of temperature contours in the canister for case (1) (Figure 8a) and case (4) (Figure $8 \mathrm{~b}$ ) provides a good illustration of this effect. Not only the overall temperature in the canister is lower in case (4), but also the temperature gradients and the temperature of the hot spots.

\subsection{Space Experiments.}

\subsubsection{Comparison with experimental data}

The same 4 cases discussed above have been considered in the Space Experiments simulations. Figure 9 indicates that the temperature history has the same features as the one of the Ground Experiments. However, the thermal arrest in the Space Experiment is not as pronounced as in the ground experiment which can be seen from comparison of Figure 5 with Figure 9. This is a result of the difference between the two experiments in the boundary conditions in the heating period. While the power input and output were kept constant in the Ground Experiments (Figure 2), the power output in the space experiment is a decreasing function of time during this period. Hence the difference of the input power and the output power is a growing function of time for the Space Experiments. This results in a higher energy stored in the canister per unit time and therefore a steeper rise of the overall temperature of the canister.

An opposite effect is observed during the cooling period. The thermal arrest in the Space Experiments is more pronounced than that in the Ground Experiments. This is a result of the power input in the Ground Experiments being negative in the cooling period while it is always positive in the Space Experiments.

\subsubsection{Effect of radiation through the void}

The presence of radiation in the void has a more significant effect in the Space Experiments than in the ground one. The reason for that is a larger surface area of the void is exposed to the incoming heat flow. The effect of radiation in the void on the temperature distribution in the canister is seen on Figure 9. As expected, the outside wall temperature is significantly lower in the presence of thermal radiation in the void. This improvement is about 30-40 K compared to $2-5 \mathrm{~K}$ for the Ground Experiments.

The void is again the location of a hot spot in the canister. As seen on Figure 10a, there is only one hot spot (compared to the hot and cold spots in the Ground Experiments) adjacent to the canister outside wall.

\subsubsection{Effect of radiation through the liquid PCM}

During the heating part of the cycle, the PCM starts to melt first in the region close to the 
canister bottom wall because of the significant $z$-component of the heat flux and the presence of the void adjacent to the outside wall. Therefore, the liquid PCM exists in the canister in the form of a horizontal layer as can be deduced by the isotherms in Figures 10a,b. Computations showed that the radiation through the liquid PCM, whether absorbing or not, does not have an effect as important as the radiation through the void. This is obvious from the comparison of the temperature histories for cases (3) and (4) with that in case (2) on Figure 9. The reason for this phenomenon is the horizontal configuration of the liquid PCM compared to the vertical one for the void. This results in the heat mostly transferred through the void rather than the liquid PCM.

\section{SUMMARY AND CONCLUSIONS}

Two sets of experimental data were examined in this paper: Ground Experiments and Space Experiments, for a cylindrical canister with thermal energy storage applications. A 2-D computational model was developed for unsteady heat transfer with phase change. An important feature of the model is using a Finite Volume Method (FVM) for the radiation heat transfer. Three different grid sizes, $10 \times 10$, $16 \times 16$ and $20 \times 20$ have been attempted. The later two cases showed that the numerical solution is grid independent. The predictions of the temperature history were obtained for four different cases regarding the radiation heat transfer: 1) no radiation in the void or the liquid $P C M, 2)$ radiation in the void only, 3) radiation in the void and the liquid PCM simultaneously and 4) same as case (3) except that the liquid $\mathrm{PCM}$ has a thermal radiation absorption coefficient of $0.84 \mathrm{~cm}^{-1}$. The predictions were evaluated against the experimental data. The following is summary of finding in this study:

\section{Ground Experiments:}

1.a The convection heat transfer is equally important to that of the radiation heat transfer; 1.b Radiation heat transfer in the liquid is found to be more significant than that in the void; 1.c Including the radiation heat transfer in the liquid resulted in lower temperatures (about $15 \mathrm{~K}$ ) and increased the melting time (about $10 \mathrm{~min}$.); 1.d Generally, most of the heat flow takes place in the radial direction; 1.e The hot spots were found (as expected) in the outer region of the void.

\section{Space Experiments:}

2.a Radiation heat transfer in the void is found to be more significant than that in the liquid (exactly the opposite to the ground experiments); 2.b Accordingly, the location and size of the void affects the performance considerably; $2 . c$ Including the radiation heat transfer in the void resulted in lower temperatures (about $40 \mathrm{~K}$ ); $2 . \mathrm{d}$ The heat flow takes place in both the radial and axial directions; 2.e The hot spots were found (as expected) in the outer region of the void.

\section{REFERENCES}

Adebiyi, G. A. [1990], "A Second-Law Study on Packed Bed Energy Storage Systems Utilizing Phase-Change Materials," ASME Journal of Solar Energy Engineering, Vol. 113, pp.146-156.

Anderson, D. A., Tannehill, J.C. and Pletcher, R.H. [1984], "Computational Fluid Mechanics and Heat Transfer," Hemisphere Publishing Corp.

Beasley, D.E., Ramanarayanan, C. and Torab, H. [1989], "Thermal Response of Packed Bed of Spheres containing a Phase-Change Material," International Journal of Energy Research, Vol. 13, pp. 253-265.

Beasley, D.E., and Clark, J.A. [1984], "Transient Response of a Packed Bed for Thermal Energy Storage," International Journal of Heat and Mass Transfer, Vol. 27, No 9, pp. 1659-1669.

Chai, J.C., Lee, H.S. and Patanker, S.V. [1994] "Finite Volume Method for Radiation Heat Transfer," Journal of Thermophysics and Heat Transfer, Vol. 8, No 3, pp. 419-425.

Kerslake, T.W. [1991], "Experiments With Phase Change Thermal Energy Storage Canisters For Space Station Freedom," 26th Intersociety Energy Conversion Engineering Conference, Boston, Mass., p. 248-261 (see also NASA TM-104427).

Kerslake, T.W. and Ibrahim, M.B. [1993], "Analysis of Thermal Energy Storage Material with Change-of-Phase Volumetric Effects," ASME Journal of Solar Energy Engineering, Vol. 115/1, pp. 22-31.

Kerslake, T.W. and Ibrahim, M.B. [1994], "Two-Dimensional Model of a Space Station Freedom Thermal Energy Storage Canister," ASME Journal of Solar Energy Engineering, Vol. 116/2, pp. 114-121. 
Modest, M.F. [1993], "Radiative Heat Transfer," McGraw-Hill, Inc.

Namkoong, D., Jacqmin, D., and Szaniszlo, A. [1995], "Effect of Microgravity on Material Undergoing Melting-Freezing - the TES Experiment," 33rd Aerospace Science Meeting and Exhibit, Reno, Nevada, January 9-12, 1995.

Ozisik, M.N. [1985], "Heat Transfer: A Basic Approach," McGraw-Hill, Inc.

Solomon, A.D. et al. [1986], "The Development of a Simulation Code for a Latent Heat Thermal
Energy Storage System in a Space Station," ORNL-6213.

Wichner,R.P.[1987], “Thermal Radiation Transfer Through LiF," Internal Correspondence, Martin Marietta Energy Systems Inc.

Wichner, P.P. et al. [1988], "Thermal Analysis of Heat Storage Canisters for a Solar Dynamic, Space Power System," ORNLTM-10665

Yao, L.S. and Prusa, J. [1989] "Melting and Freezing," Advances in Heat Transfer, Vol. 19, pp. 1-95.

Table I. Test Canister Design Features, Ground Experiment and Space Experiment

\begin{tabular}{|c|l|l|}
\hline \multicolumn{1}{|c|}{ Feature } & Ground Experiments & Space Experiments \\
\hline Material of Construction & Haynes Alloy 188 & Haynes Alloy 188 \\
\hline Outer DiameterMall Thickness & $4.98 / 0.129(\mathrm{~cm})$ & $6.96 / 0.102(\mathrm{~cm})$ \\
\hline Inner Diameter $/$ Wall Thickness**/Rod Diameter & $2.07 / 0.261(\mathrm{~cm}) / \mathrm{N} / \mathrm{A}$ & $3.81 / 0.102 / 3.59(\mathrm{~cm})$ \\
\hline Length / Side Wall Thickness & $2.43 / 0.091(\mathrm{~cm})$ & $6.94 / 0.102(\mathrm{~cm})$ \\
\hline Phase Change Material (PCM) & $\mathrm{LiF}-20 \% \mathrm{CaF} / \mathrm{F}$ \\
\hline PCM Melting Point / Heat of Fusion & $1042 \mathrm{~K} / 816 \mathrm{~J} / \mathrm{g}$ & $1121 \mathrm{~K} / 1037 \mathrm{~J} / \mathrm{g}$ \\
\hline PCM Mass / Total Canister Mass & $53 / 137(\mathrm{~g})$ & $265 / 543(\mathrm{~g})$ \\
\hline Cycle Time (\% time Heating) & $91.1 \mathrm{~min}(60 \%)$ & $131 \mathrm{~min}(58 \%)$ \\
\hline
\end{tabular}

* - Cooling air tube * - Thickness of canister inner wall plus cooling air tube wall 


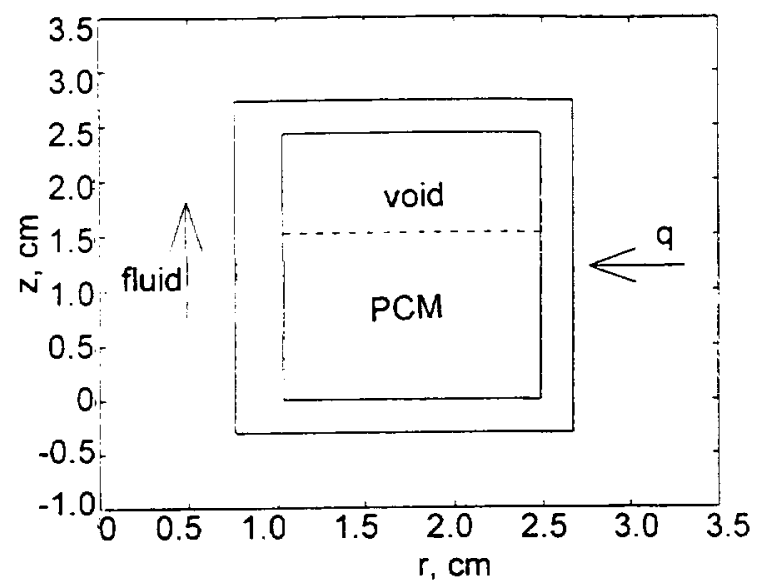

Figure 1. Geometry of the Ground Experiments with the Void Model.

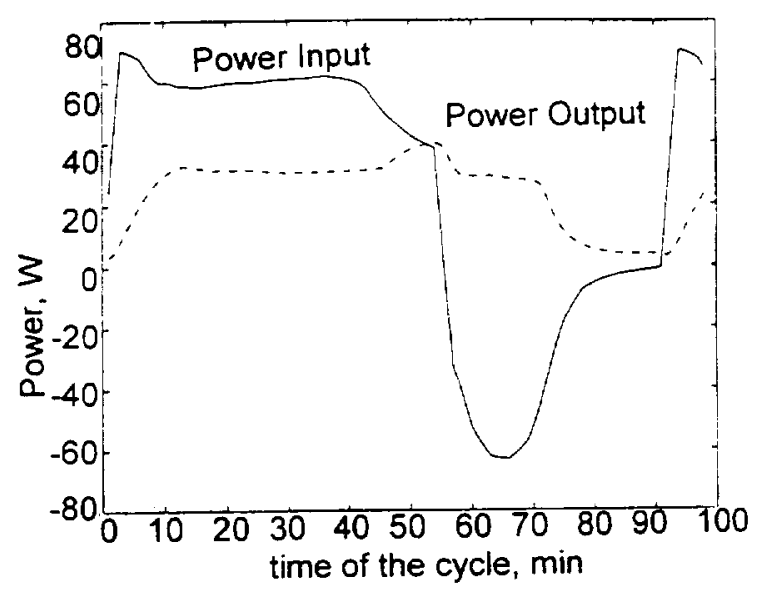

Figure 2. Power Input and Output for the Ground Experiments.

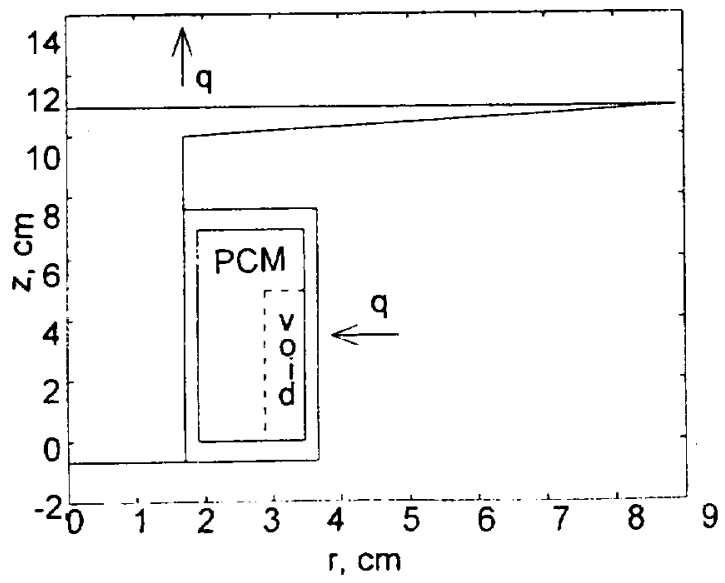

Figure 3. Geometry of the Space Experiments with the Void Model.

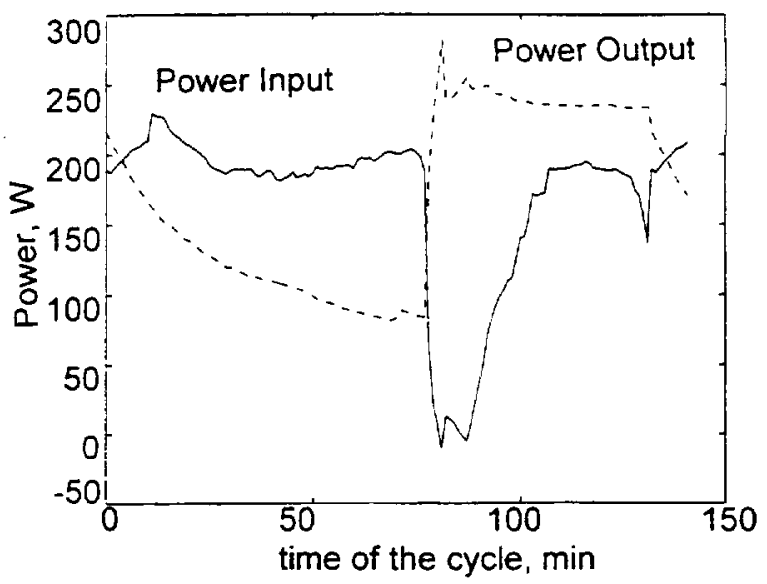

Figure 4. Power Input and Output for the Space Experiments.

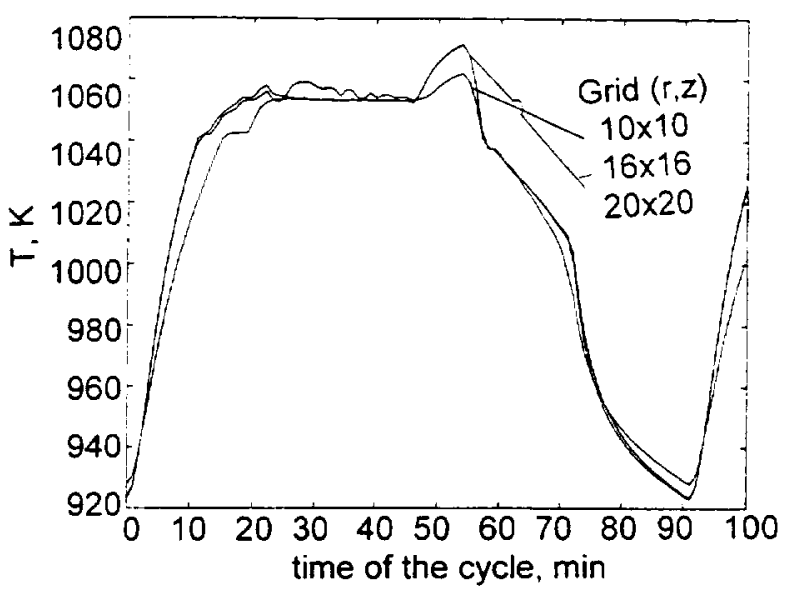

Figure 5. Computational Canister Temperature Data with Different Grids, Ground Experiments

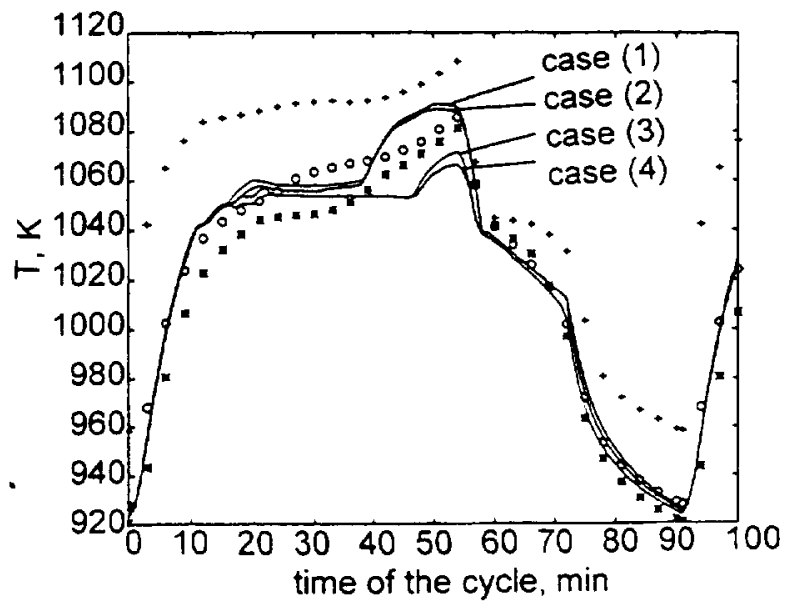

Figure 6. Experimental (symbols) and Computational Canister Temperature Data, Ground Experiments. 


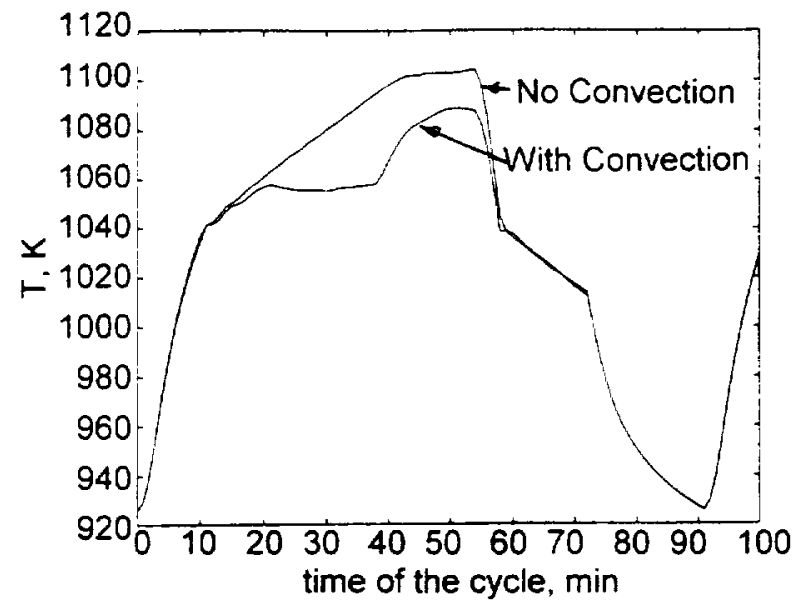

Figure 7. Effect of Natural Convection on Canister Temperature, Ground Experiments.

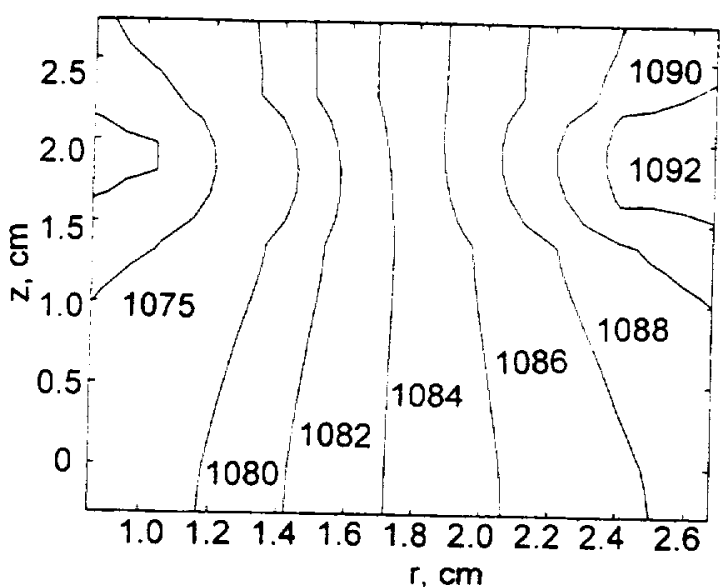

Figure 8a. Computational Canister Temperature Contours, Ground Experiments, time $=50$ min, Case (1).

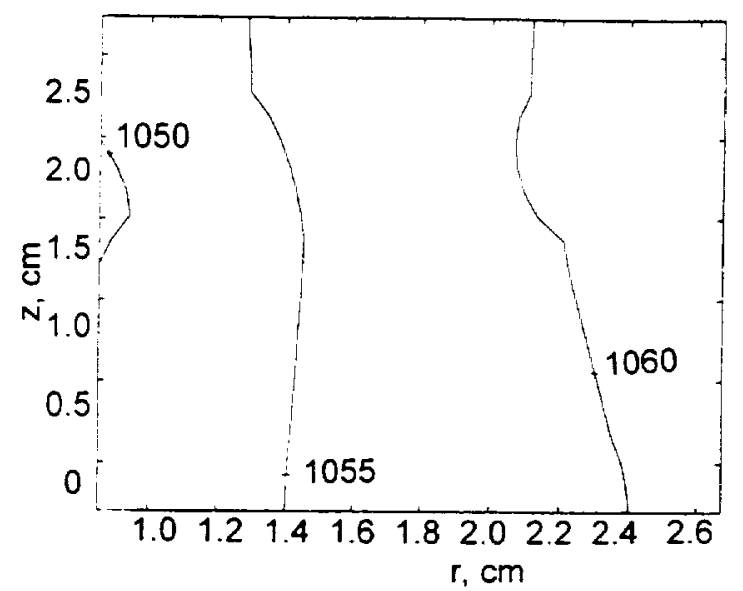

Figure $8 \mathrm{~b}$. Computational Canister Temperature Contours, Ground Experiments, time $=50 \mathrm{~min}$, Case (4).

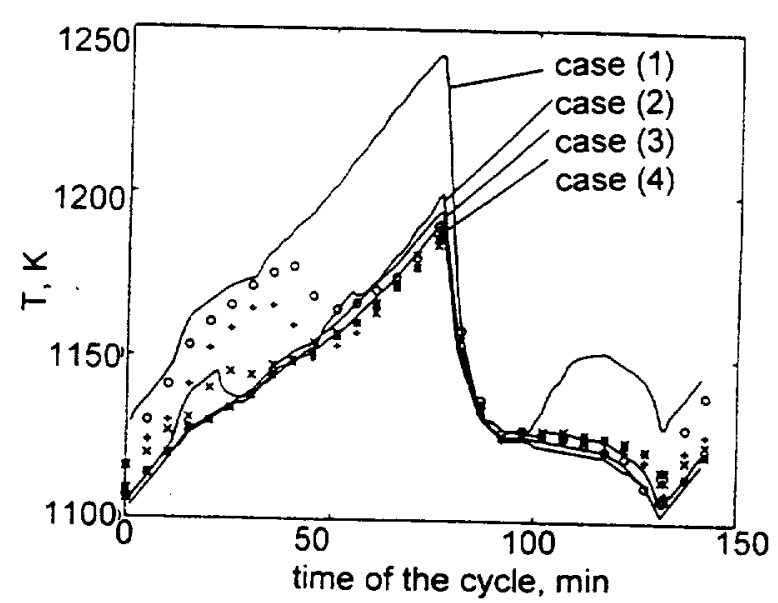

Figure 9. Experimental (Symbols) and Computational Canister Temperature Data, Space Experiments.

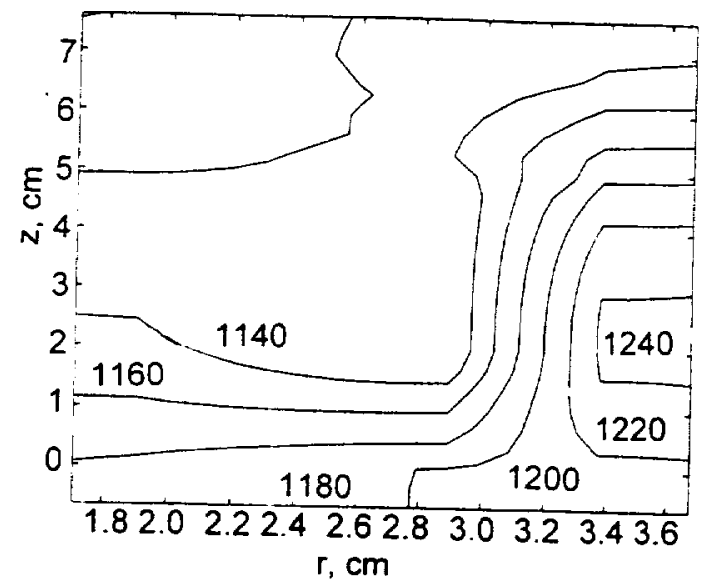

Figure 10a. Computational Canister Temperature Contours, Space Experiments, time $=76 \mathrm{~min}$, Case (1).

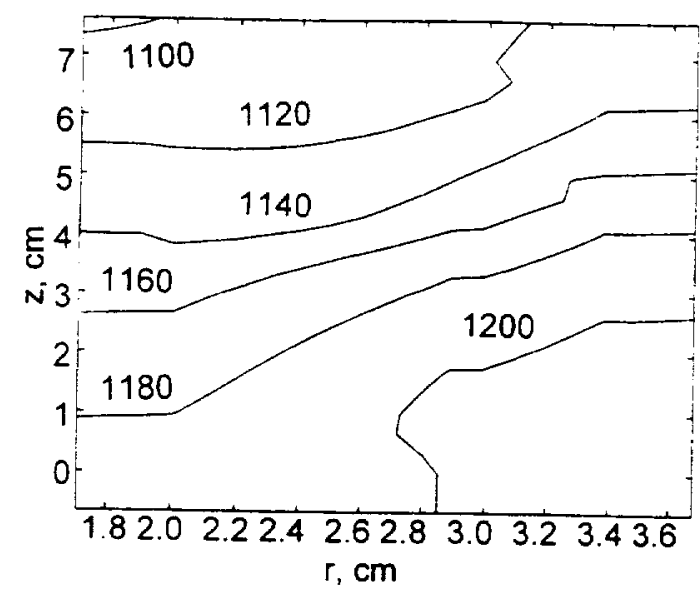

Figure 10b. Computational Canister Temperature Contours, Space Experiments, time $=76 \mathrm{~min}$, Case (4). 
Public reporting burden for this collection of information is estimated to average 1 hour per response, including the bime lor reviewing instructions, searching existing data sources,

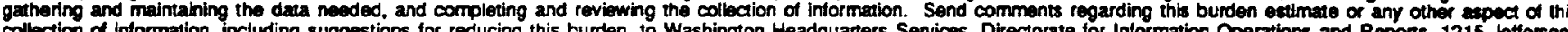
Davis Highway, Sulte 1204, Arlington, VA 22202-4302, and to the Otfice of Management and Budget, Paperwork Reduction Project (0704-0188), Washinglon. DC 20503.

\begin{tabular}{|l|l|l}
\hline 1. AGENCY USE ONLY (Leave blank) & $\begin{array}{r}\text { 2. REPORT DATE } \\
\text { December } 1996\end{array}$ & $\begin{array}{r}\text { 3. REPORT TYPE AND DATES COVERED } \\
\text { Technical Memorandum }\end{array}$ \\
\hline
\end{tabular}

\section{TITLE AND SUBTITLE}

5. FUNDING NUMBERS

Experimental and Computational Investigations of Phase Change Thermal Energy Storage Canisters

\section{AUTHOR(S)}

WU-547-10-41

Mounir Ibrahim, Thomas Kerslake, Pavel Sokolov, and Carol Tolbert

7. PERFORMING ORGANIZATION NAME(S) AND ADDRESS(ES)

National Aeronautics and Space Administration

Lewis Research Center

Cleveland, Ohio 44135-3191

8. Performing organization REPORT NUMBER

E-10571

9. SPONSORING/MONITORING AGENCY NAME(S) AND ADDRESS(ES)

10. SPONSORINGMONITORANG AGENCY REPORT NUMBER

National Aeronautics and Space Administration

Washington, DC 20546-0001

NASA TM-107382

\section{SUPPLEMENTARY NOTES}

Prepared for the International Congress of Fluid Dynamics and Propulsion sponsored by the American Society of Mechanical Engineers and Cairo University, Cairo, Egypt, December 29-31, 1996. Mounir Ibrahim and Pavel Sokolov, Cleveland State University, Cleveland, Ohio 44115 (work funded by NASA Grant NAG3-1756); Thomas Kerslake and Carol Tolbert NASA Lewis Research Center. Responsible person. Thomas Kerslake, organization code 6920, (216) 433-5373.

12a. DISTRIBUTIONAVAILABILTY STATEMENT

12b. DISTRIBUTION CODE

Unclassified - Unlimited

Subject Categories 20 and 34

This publication is available from the NASA Center for AeroSpace Information, (301) 621-0390.

\section{ABSTRACT (Maximum 200 words)}

Two sets of experimental data were examined in this paper, ground and space experiments, for cylindrical canisters with thermal energy storage applications. A 2-D computational model was developed for unsteady heat transfer (conduction and radiation) with phase-change. The radiation heat transfer employed a finite volume method. The following was found in this study: 1) Ground Experiments, the convection heat transfer is equally important to that of the radiation heat transfer; Radiation heat transfer in the liquid is found to be more significant than that in the void; Including the radiation heat transfer in the liquid resulted in lower temperatures (about $15 \mathrm{~K}$ ) and increased the melting time (about $10 \mathrm{~min}$.); Generally, most of the heat flow takes place in the radial direction. 2) Space Experiments, Radiation heat transfer in the void is found to be more significant than that in the liquid (exactly the opposite to the Ground Experiments); Accordingly, the location and size of the void affects the performance considerably; Including the radiation heat transfer in the void resulted in lower temperatures (about $40 \mathrm{~K}$ ).

\section{SUBJECT TERMS}

Phase change materials; Heat storage; Computational fluid dynamics; Radiation heat transfer; Salts

\begin{tabular}{|c|c|c|}
\hline $\begin{array}{c}\text { 17. SECURTY CLASSIFICATION } \\
\text { OF REPORT } \\
\text { Unclassified }\end{array}$ & $\begin{array}{c}\text { 18. SECURTY CLASSIFICATION } \\
\text { OF THIS PAGE } \\
\text { Unclassified }\end{array}$ & $\begin{array}{c}\text { 19. SECUAITY CLASSIFICATION } \\
\text { OF ABSTRACT } \\
\text { Unclassified }\end{array}$ \\
\hline
\end{tabular}

